\title{
Aspectos metabólicos e funcionais do zinco na síndrome de Down
}

\author{
Metabolic and functional aspects of zinc \\ in Down syndrome
}

Raynério Costa MARQUES

Dilina do Nascimento MARREIRO²

RE S U M O

Este estudo relata os aspectos funcionais do zinco, bem como a participação desse mineral nas alterações metabólicas presentes em indivíduos portadores de Síndrome de Down. A maioria dos trabalhos realizados observou que o estado nutricional relativo ao zinco nesses pacientes está inadequado, com alterações no sistema antioxidante, imunológico e no metabolismo dos hormônios da tireóide. Estudos in vitro apontam que o zinco participa como cofator da enzima deiodinase tipo II na conversão periférica de Tiroxina em Triiodotironina, e que essa reação está diminuída em indivíduos portadores de Síndrome de Down, o que contribui para a manifestação de distúrbios, como o hipotireoidismo subclínico. As alterações na compartimentalização do zinco no organismo desses indivíduos também favorecem a expressão excessiva da enzima cobre/zinco (Cu/Zn) superóxido dismutase, com aumento do estresse oxidativo, e ainda alterações no sistema imune. Na Síndrome de Down, tem sido demonstrada melhora no metabolismo dos hormônios tireoidianos e na função imune, após a suplementação com zinco. Portanto, o papel metabólico do zinco na Síndrome de Down deve ser mais pesquisado, tendo em vista que esse mineral pode contribuir no controle das alterações metabólicas comumente presentes em indivíduos portadores dessa síndrome.

Termos de Indexação: estado nutricional; metabolismo; Síndrome de Down; zinco.

\section{A B S T R A C T}

This study reports the functional aspects of zinc as well as its participation in the metabolic changes present in individuals with Down syndrome. Most of the studies performed observed that the nutritional status related to zinc in these patients is inadequate, with changes in the antioxidant and immunological systems and in the metabolism of thyroid hormones. In vitro studies show that zinc participates as a cofactor of the enzyme deiodinase type II in the peripheral conversion of thyroxin into triiodothyronine, and that this reaction

\footnotetext{
1 Mestrando, Centro de Ciências da Saúde, Departamento de Nutrição, Universidade Federal do Piaui. Teresina, PI, Brasil.

2 Departamento de Nutrição, Universidade Federal do Piauí. Campos Universitário Ministro Petrônio Portela, Bloco 13, s/n, 64049-550, Ininga, Teresina, PI, Brasil. Correspondência para/Correspondence to: D.N. MARREIRO. E-mail:<marreiro@usp.br>.
} 
is decreased in individuals with Down syndrome, contributing to the manifestation of disorders such as subclinical hypothyroidism. Changes in zinc compartmentation in the body of these individuals also favor an excessive expression of the copper/zinc enzyme (Cu/Zn) superoxide dismutase, with increased oxidative stress, and also changes in the immune system. In Down syndrome, zinc supplementation has been shown to improve thyroid hormone metabolism and immune function. Therefore, the metabolic role of zinc in Down syndrome should be further researched, knowing that this mineral can.

Indexing terms: nutritional state; metabolism; Down Syndrom; zinc.

\section{N T R O D U Ç Ã O}

A Síndrome de Down é uma doença cromossômica, caracterizada pela presença e expressão de três cópias de genes localizados no cromossomo 21, que constitui uma das causas mais freqüentes de deficiência mental, compreendendo cerca de $18 \%$ do total de deficientes mentais em instituições especializadas ${ }^{1,2}$.

Nos anos recentes, percebe-se um crescente interesse no que diz respeito às desordens hormonais, bioquímicas e nutricionais presentes na Síndrome de Down. Estudos têm procurado elucidar os mecanismos envolvidos na fisiopatologia de doenças associadas a essa síndrome, assim como os fatores contribuintes para o comprometimento do crescimento e desenvolvimento. Nesse sentido, têm sido demonstradas alterações na função e metabolismo dos hormônios da glândula tireóide, caracterizando o hipotireoidismo subclínico ${ }^{3}$. Paralelamente, também já foram evidenciadas alterações no metabolismo de zinco na Síndrome de Down, com reduzidas concentrações desse mineral no plasma e na urina ${ }^{4}$. 0 zinco participa do metabolismo energético e na regulação da expressão gênica, como componente catalítico de mais de 300 metaloenzimas ${ }^{5,6}$.

Para alguns pesquisadores, os distúrbios presentes na Síndrome de Down podem ser agravados pela deficiência de zinco ${ }^{7}$. Esse mineral participa como cofator da deiodinase tipo II, uma das enzimas que regula a conversão de tiroxina (T4) a triiodotironina (T3) ${ }^{8}$.

A contribuição do zinco ao metabolismo desses hormônios desperta o interesse pelo estudo do mineral nas alterações metabólicas e fisiológicas normalmente presentes na Síndrome de
Down. Portanto, a intenção deste estudo foi avaliar os avanços dos conhecimentos no que diz respeito ao estado nutricional relativo ao zinco, bem como a participação desse mineral nas alterações bioquímicas, metabólicas e/ou hormonais presentes em pacientes com trissomia do 21 .

\section{Aspectos metabólicos do zinco}

A captação do zinco pela superfície da borda em escova ocorre por meio de dois mecanismos de transporte: processo mediado por transportadores e por difusão simples, que varia em sua importância conforme a concentração desse mineral presente na dieta. O mecanismo mediado por carreador predomina em situação de baixa concentração de zinco na dieta, enquanto que a absorção por difusão simples é predominante quando a concentração desse mineral é elevada?.

Dentro das células intestinais, o zinco liga-se à metalotioneína, proteína responsável pela regulação homeostática de sua absorção. A expressão gênica dessa proteína é estimulada por hormônios, como, por exemplo, os glicocorticóides, e pela alta ingestão alimentar de zinco. Outra proteína presente na mucosa intestinal é a proteína intestinal, rica em cisteína (CRIP). Essa proteína liga-se ao zinco dentro do enterócito e tem função de carreador intracelular, aumentando a velocidade de absorção. Quando em estado de elevada concentração de zinco no organismo, esse mineral permanece ligado à metalotioneína, sendo, em seguida, excretado nas fezes, juntamente com as células intestinais descamadas. Por outro lado, em situação de deficiência, o zinco é transferido à CRIP e é, então, transportado para a corrente sangüínea ${ }^{10}$. 
O zinco da dieta está associado com inúmeros outros fatores que podem promover ou dificultar sua absorção, que ocorre em todo o intestino delgado. A presença de aminoácidos, como a cisteina e a histidina, melhoram sua biodisponibilidade. Por outro lado, o fitato presente nos alimentos (farelos, cereais de grãos integrais e leguminosas) dificulta essa disponibilidade. Esses compostos possuem carga negativa, que mantém um alto potencial de ligação estável com cátions, tais como o zinco. Assim, a relação fitato: zinco acima de 10:1, pode afetar a absorção desse mineral5,11. Em um estudo realizado com 21 indivíduos, Lee et al..$^{12}$ demonstraram que a absorção de zinco depende da sua concentração no lúmen e que a porção do intestino delgado em que ocorre a maior parte da absorção é o jejuno.

Outros fatores também podem influenciar a captação e o transporte celular de zinco, quais sejam: fatores dietéticos, como a forma química do elemento na dieta, presença de ligantes antagonistas (taninos, polifenóis, oxalatos e fitatos), presença de ligantes facilitadores (aminoácidos, ácidos orgânicos), fatores genéticos, que influenciam a absorção, e ainda os fatores sistêmicos, entre eles o estado de anabolismo ou catabolismo, alterações endócrinas, função hepática, função renal, estresse e infeções ${ }^{13}$.

Genes envolvidos na síntese de proteínas e que participam do transporte de zinco foram clonados recentemente. O primeiro gene a ser clonado foi o gene do transportador ZnT-1, tendo sido descoberto em 1995 por Palmiter \& Findley ${ }^{14}$. O ZnT-1 é encontrado em todos os tecidos e está associado com o efluxo de zinco, sendo que nos eritrócitos e nas células tubulares renais localiza-se, predominatemente, na membrana basolateral, na qual regula, respectivamente, a absorção e reabsorção de zinco ${ }^{14}$. Outros transportadores específicos também já foram identificados, o ZnT-2, ZnT-3 e ZnT-4. O transportador de cátions divalentes 1 (DCT1) que participa do transporte do ferro também exibe atividade de transporte para outros minerais, como, por exemplo, o zinco ${ }^{15}$.
Após absorção e liberação da célula intestinal pela membrana basolateral, por meio dos transportadores, o zinco passa para os capilares mesentéricos e é transportado no sangue portal, sendo captado pelo fígado e, subseqüentemente, distribuído para outros tecidos ${ }^{16}$. No plasma, o zinco é carreado ligado a proteínas, como a albumina, $\alpha_{2}$ macroglobulina e aminoácidos, especialmente a histidina e a cistina ${ }^{17}$. A excreção de zinco ocorre primariamente pelo trato gastrointestinal.

O conteúdo total de zinco no organismo varia de 1,5 a $2 \mathrm{~g}$, sendo que $80 \%$ desse é encontrado no músculo esquelético e osso. Esse mineral é, também, encontrado no intestino, nos fluídos e nas secreções do organismo. A maior parte do zinco no organismo está ligada a metaloenzimas. Aproximadamente $80 \%$ do zinco presente no sangue encontra-se nos eritrócitos.

A avaliação do estado nutricional em relação ao zinco, compreende medidas do consumo alimentar, concentrações de zinco no plasma, nos leucócitos, neutrófilos, eritrócitos e na urina, e ainda, por meio de parâmetros funcionais, como a análise da atividade de metaloenzimas: anidrase carbônica, fosfatase alcalina, superóxido dismutase, metalotioneinas e carboxipeptidases. Apesar da existência de vários parâmetros biológicos, ainda existem muitas dificuldades para determinação do estado nutricional dos indivíduos em relação a esse mineral ${ }^{18}$.

A concentração de zinco no plasma é o índice que mais tem sido utilizado para avaliar o estado nutricional relativo a esse mineral e responde, rapidamente, a qualquer variação desse. Entretanto, esse índice é influenciado, tanto pelo estado fisiológico quanto pelo patológico ${ }^{18}$. A concentração de zinco eritrocitário reflete alterações a médio e longo prazos nos estoques desse mineral no organismo, e a variação indicada é devida à meia-vida mais longa dos eritrócitos (120 dias $)^{19}$. 
Outro parâmetro utilizado na avaliação do zinco corpóreo é a excreção urinária. Esse índice diminui à medida que ocorre o desenvolvimento de uma deficiência do mineral. Entretanto, em algumas condições patológicas pode ocorrer hiperzincúria independentemente da manifestação de deficiência de zinco, como, por exemplo, na anemia falciforme, no diabetes mellitus e na cirrose $^{20}$.

A avaliação do consumo alimentar do mineral pode ser feita por meio da utilização de tabelas de alimentos ou pela técnica da porção em duplicata, que oferece resultados mais confiáveis que o das tabelas ${ }^{21}$. Esta técnica consiste em obter uma duplicata exatamente igual à dieta ingerida e analisar quantitativamente os minerais de interesse.

\section{Funções fisiológicas do zinco}

O papel do zinco na nutrição humana tem sido cada vez mais ressaltado, e tem havido um progresso dos conhecimentos no que diz respeito aos aspectos bioquímicos, imunológicos e clínicos. A importância desse mineral foi demonstrada com a descoberta de processos metabólicos, envolvendo esse nutriente em diversas atividades enzimáticas. Ele participa do metabolismo energético, como componente catalítico de mais de 300 metaloenzimas nos tecidos humanos, e como componente estrutural de diversas proteínas, hormônios e nucleotídeos ${ }^{22}$.

Entre as enzimas das quais o zinco faz parte estão a anidrase carbônica, que foi a primeira dependente de zinco a ser descoberta, além da proteína $C$ quinase, fostatase alcalina, carboxipeptidases, álcool desidrogenase, superóxido dismutase e transcriptase reversa ${ }^{22-26}$.

A participação do zinco nos sistemas enzimáticos envolvidos na síntese e degradação de proteínas e na transformação de carboidratos em lipídios e ácidos nucléicos, demonstra a essencialiadade desse mineral para o crescimento, a reprodução e a maturação sexual. Nesse sentido, já foi demonstrado, por meio de diversas pesquisas, o papel do zinco na organização polimérica de macromoléculas, como DNA (ácido desoxiribonucléico) e RNA (ácido ribonúcléico), sendo indispensável para a atividade de enzimas envolvidas diretamente com a síntese de DNA e RNA, como, por exemplo, a RNA polimerase.

Nessa abordagem, a importância do zinco na nutrição humana é notada não somente para o crescimento e desenvolvimento normais, mas também para a imunidade, defesa antioxidante, manutenção do apetite, do paladar, da capacidade de cicatrização de feridas e para a visão noturna22,27.

O zinco contribui na estabilização de membranas estruturais e na proteção celular, prevenindo a peroxidação lipídica. O papel fisiológico desse mineral como antioxidante é evidenciado, fundamentalmente, por dois mecanismos: proteção dos grupos sulfidrilos contra oxidação e inibição da produção de espécies reativas de oxigênio por metais de transição, reforçando, assim, o papel do zinco como estabilizador da membrana plasmática e de outras membranas e organelas encapsuladas ${ }^{28}$.

Pesquisas demonstram que a quantidade de zinco presente na dieta pode influenciar a expressão gênica ${ }^{17}$, podendo ser diretamente, por meio de ligação com fatores de transcrição, ou

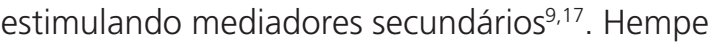
\& Cousins $^{10}$, em 1992, também verificaram que a manutenção e a replicação do material genético (DNA e RNA) e o uso de informação genética para gerar proteínas específicas eram também dependentes desse mineral.

Os resultados de vários estudos demonstram a importância da proteção dos grupos tiol na tradução do sinal da insulina, sendo que o zinco participa nessa proteção e, assim, exerce um efeito benéfico adicional sobre a sensibilidade tecidual a esse hormônio. A importância desse mineral na proteção dos grupos tiols, em conjunto com outros mecanismos de interação do zinco e metabolismo de glicose, abre perspectivas para a sua utilização em pacientes diabéticos, para 
melhorar o controle metabólico, ou em estágios de intolerância à glicose, para impedir a progressão para o diabetes ${ }^{6}$.

\section{Estado nutricional relativo ao zinco na Síndrome de Down}

Vários trabalhos têm demonstrado alterações na distribuição tecidual de zinco em indivíduos que apresentam Síndrome de Down (SD), o que exerceria papel de extrema relevância em grande parte das manifestações clínicas dessa síndrome.

A avaliação do estado nutricional relativo ao zinco em indivíduos portadores de SD, tem sido conduzida utilizando diversos parâmetros bioquímicos, quais sejam: plasma, soro, cabelo, saliva, eritrócito e urina ${ }^{29-31}$.

Desde 1988, Purice et al. ${ }^{31}$ observaram baixa concentração plasmática de zinco em crianças com SD. Assim como esse, outros estudos também demonstram reduzidas concentrações de zinco no cabelo, soro e plasma de indivíduos portadores dessa síndrome ${ }^{32,33}$.

As concentrações de zinco no plasma foram avaliadas em 43 crianças portadoras de SD e comparadas com 40 controles, por Soto-Quintana et al. ${ }^{34}$. Os autores verificaram que houve uma diminuição significativa nos níveis desse mineral no plasma de crianças com SD, quando comparadas com o grupo controle.

Em estudo conduzido por Yenigun et al. ${ }^{33}$, foi avaliada a concentração de zinco no cabelo de 19 crianças portadoras de SD e comparada com 11 controles. A concentração de zinco encontrada no cabelo das crianças que apresentavam a síndrome foi significativamente menor do que a encontrada no grupo controle.

Em 2002, Lima ${ }^{30}$ avaliou o estado nutricional relativo ao zinco em crianças com Síndrome de Down, utilizando como parâmetros bioquímicos o plasma, o eritrócito e a urina. Os resultados desse estudo mostraram que mais de $80 \%$ dessas crianças apresentavam concentrações de zinco inferiores aos valores considerados como referência, de 70 a $110 \mu \mathrm{g} / \mathrm{dl}$. Já a avaliação da concentração de zinco nos eritrócitos, mostrou que $74,3 \%$ das crianças apresentavam valores acima da normalidade.

De forma semelhante, no estudo conduzido por Purice et al. ${ }^{31}$ foi avaliada a concentração de zinco e cobre nos eritrócitos de 24 crianças portadores de Síndrome de Down e observou-se elevada concentração de zinco nos eritrócitos dessas crianças, quando comparadas com o grupo controle.

Siqueira et al..$^{35}$ avaliaram a concentração de zinco na saliva de 22 crianças portadoras de Síndrome de Down, com idade entre 6 e 10 anos, e compararam com um grupo controle. Os resultados desse estudo não revelaram diferença estatística significativa entre os grupos em relação à concentração de zinco.

\section{Zinco, função da glândula tireóide e Síndrome de Down}

O interesse pelo desenvolvimento de estudos sobre zinco e Síndrome de Down baseia-se no fato desse mineral ser importante para várias funções orgânicas, as quais encontram-se alteradas em indivíduos portadores dessa síndrome, como, por exemplo, aquelas desenvolvidas no sistema imune, endócrino e hematológico ${ }^{33}$.

Os estudos que relacionavam esse mineral com a Síndrome de Down sugeriam que as alterações encontradas na sua distribuição tecidual estariam relacionadas com distúrbios na atividade dos hormônios da tireóide, principalmente no que diz respeito à ação desses hormônios nos tecidos.

Vários trabalhos mostraram a participação do zinco no metabolismo dos hormônios da glândula tireóide. Em 1990, Napolitano et al. ${ }^{32}$ avaliaram o efeito da suplementação com sulfato de zinco sobre a função da glândula tireóide, em portadores da Síndrome de Down que apresentavam hipotireoidismo subclínico e deficiência de zinco. Verificaram uma redução nos níveis de T3 
reverso, diminuindo a incidência do hipotireoidismo subclínico.

Licastro et al. ${ }^{36}$, em 1993, avaliaram o efeito da suplementação com zinco sobre os níveis dos hormônios da glândula tireóide em 51 crianças com Síndrome de Down e compararam com o grupo controle $(n=15)$. Antes da intervenção, os autores verificaram uma redução na concentração de zinco plasmático e T3 reverso, um aumento do TSH e níveis normais de T3 e T4. Após a suplementação com sulfato de zinco, os níveis de TSH, T3 reverso e zinco plasmático foram restaurados.

A participação do zinco na conversão dos hormônios tireoidianos também foi evidenciada por Nishiyama et al. ${ }^{8}$, em 1994 . Os autores avaliaram o efeito da suplementação com zinco em pacientes com alterações no metabolismo dos hormônios da tireóide. Encontraram melhora dessas anormalidades após a intervenção. A conversão periférica de T4 a T3 é regulada pelas iodotironinas deiodinases tipo I e II. A primeira é uma enzima dependente de selênio, e é possível que a deiodinase tipo II seja uma proteína dependente de Zn ou, então, necessite desse mineral como cofator no processo de deiodinação. Sugerem, portanto, uma participação do zinco, além do selênio e do iodo, no metabolismo dos hormônios tireoidianos.

Em outro estudo conduzido no ano de 1999, por Bucci et al. ${ }^{4}$, foi avaliado o efeito da suplementação com zinco em indivíduos com Síndrome de Down, hipozincêmicos e com hipotireoidismo subclínico. Os autores observaram um aumento da função tireoideana, com níveis gradativamente diminuídos de TSH, e uma correlação positiva entre as concentrações de zinco e os níveis desse hormônio.

Licastro et al. ${ }^{37}$ estudaram as anormalidades da glândula tireóide e o nível plasmático de zinco em 43 crianças com síndrome de Down. Os autores observaram uma hipozincemia e reduzidas concentrações séricas dos hormônios tireoidianos.
Diferentemente, a suplementação com zinco em indivíduos com Síndrome de Down não demonstrou diferença estatística significativa em relação aos níveis dos hormônios tireoidianos, TSH, T3 e T4 totais e livres entre as crianças que apresentavam hipozincemia e concentrações adequadas desse mineral ${ }^{7}$.

\section{Zinco, enzima superóxido dismutase e Síndrome de Down}

Diversos estudos têm sido conduzidos visando esclarecer os mecanismos envolvidos nas alterações observadas nas enzimas que compõem o sistema de defesa antioxidante em pacientes com Síndrome de Down. Nesse sentido, já foi observado um aumento em torno de $50 \%$ da atividade da Cu/Zn superóxido dismutase nos eritrócitos desses indivíduos, devido à expressão aumentada do gene em células de pacientes com a presença adicional de um cromossomo $21^{38}$.

Já Neve et al. ${ }^{39}$ avaliaram as concentrações plasmáticas e eritrocitária de zinco e cobre em 29 indivíduos com Síndrome de Down, e em um grupo controle $(n=32)$. Além disso, investigaram a relação entre esses parâmetros e a atividade da enzima superóxido dismutase. Os autores verificaram reduzidas concentrações de zinco e cobre no plasma dos pacientes com trissomia 21 e elevado nível desses minerais nos eritrócitos, quando comparadas aos controles. Os pesquisadores sugeriram que esse aumento poderia ser explicado pela elevada atividade da enzima Cu/Zn superóxido dismutase verificada nessas células.

Um trabalho desenvolvido por De la Torre et al. ${ }^{38}$ investigou a atividade da $\mathrm{Cu} / Z \mathrm{n}$ superóxido dismutase (Cu/Zn-SOD) de uma população de pacientes com SD, apresentando cariótipo de trissomia completa e parcial do cromossomo 21 , translocação e mosaicismo, para confirmar o efeito da dosagem do gene para a SOD. Na população com trissomia completa do cromossomo 21, a atividade da SOD foi aumentada em $42 \%$; na população com trissomia parcial, translocação e 
mosaicismo, a atividade da SOD era normal. $\mathrm{Na}$ população diagnosticada como SD, mas não cariotipada, a atividade da SOD foi aumentada em $28 \%$. Nenhuma diferença foi encontrada entre o gênero e a idade.

Em outro estudo 40 foram avaliadas a atividade da Cu/Zn-SOD e as concentrações plasmáticas de seus cofatores (zinco e cobre), em 20 indivíduos com Síndrome de Down e em 15 controles. Os níveis de cobre no plasma, bem como a atividade da superóxido dismutase, estavam diminuídos, comparados com um grupo controle $(n=15)$. Já em relação ao zinco, não foi verificada diferença na sua concentração, em comparação ao grupo controle.

O envelhecimento rápido na SD é uma característica bastante comum, que pode ser atribuída à hiper expressão de Cu/Zn-SOD1. A superóxido dismutase (SODs) está envolvida na proteção celular quanto à toxicidade de oxigênio. Porém, vários documentos relataram que a hiperexpressão de Cu/Zn-SOD também pode causar danos oxidativos às células. Como conseqüência, a formação excessiva de radicais hidroxil poderá levar à lesão oxidativa, aumentando a freqüência de danos ao DNA, induzida por peróxido de hidrogênio ( $\mathrm{H} 2 \mathrm{O} 2)$ e cobre e levando, portanto, ao envelhecimento rápido ${ }^{41}$.

O estresse oxidativo é uma situação decorrente de um desequilíbrio entre o sistema pró-oxidante-antioxidante. Isso pode ser devido a fontes exógenas de radicais livres ou a estresse endógeno. Tais danos podem atingir todos os tipos de moléculas, incluindo DNA, lipídeos, proteínas e carboidratos. Portanto, o estresse oxidativo pode estar envolvido em processos tais como: mutagênese, peroxidação lipídica, oxidação de proteínas e danos de carboidratos, e pode ser conseqüência da depleção dos níveis de antioxidantes, ou do aumento da formação de espécies reativas de oxigênio, contribuindo para os processos de enveIhecimento e doenças ${ }^{42}$.

Nesse contexto, no estudo de Antonucci et al. ${ }^{43}, 31$ pacientes com Síndrome de Down foram avaliados com o intuito de estudar a presença de apoptose nas células do sangue, relacionando-a aos níveis de zinco no plasma. Vinte pacientes foram submetidos a uma terapia com sulfato de zinco (ZnSO4) e 19 ficaram sem o respectivo tratamento. Antes da intervenção, observou-se a presença de apoptose nas células do sangue desses pacientes, enquanto que após a suplementação foi verificada uma redução no número de células apoptóticas. Esses resultados sugerem que o processo de células programadas para morrer, no sangue de pacientes com Síndrome de Down, está relacionado com os níveis de zinco no plasma, uma vez que a concentração adequada do mineral inibe a atividade de endonucleases e, conseqüentemente, a fragmentação de DNA.

\section{Zinco, sistema imune e Síndrome de Down}

Diversas pesquisas têm demonstrado que indivíduos com cromossomo 21 excedente apresentam maior vulnerabilidade a infecções do que a população em geral, sugerindo a possível presença de alguma alteração imunológica ${ }^{43-45}$.

O zinco é um cofator de várias enzimas que participam de sistema imune. Reduzidas concentrações séricas desse elemento são apontadas como possível causa da deficiência na quimiotaxia observada na Síndrome de Down, uma vez que esse mineral atua como um cofator na resposta das células $\mathrm{T}^{44}$.

Bjorksten et al. ${ }^{45}$ avaliaram o efeito da suplementação com sulfato de zinco durante 2 meses, em 12 indivíduos com Síndrome de Down que apresentavam reduzidas concentrações séricas de zinco e deficiência na função imune. Após a intervenção, os autores observaram aumento dos níveis séricos de zinco, melhora na resposta dos linfócitos $T$ e na função quimiotáxica dos neutrófilos.

As concentrações de imunoglobulinas foram avaliadas em 110 indivíduos com Síndrome de Down, em diferentes faixas etárias, divididas 
em 3 grupos: (grupo 1=1-9 anos; grupo 2=6-15 anos; grupo 3=15-35 anos) e comparadas com o grupo controle no mesmo estágio de vida $(n=110)$. As concentrações séricas de IgA foram significativamente mais altas em todos os grupos com $S D$, sendo que a IgA se encontrava mais elevada nos grupos 1 e 2 . Os níveis séricos de zinco foram menores em todos os grupos com SD ${ }^{46}$.

Licastro et al. ${ }^{47}$ estudaram os efeitos de uma suplementação oral de zinco, com duração de quatro meses, sobre os parâmetros imunológicos de 21 indivíduos com SD, com idades variando entre 7 e 15 anos. $O$ zinco foi administrado na forma de $1 \mathrm{mg}$ de sulfato por quilograma de peso corporal por dia. Níveis plasmáticos do metal foram monitorados durante todo o procedimento, a fim de evitar possível acúmulo. Os autores observaram melhoras em alguns dos parâmetros controlados: atividade proliferativa dos linfócitos, níveis de timulina e funções dos neutrófilos, ao lado de um número menor de quadros infecciosos e da incidência de estados febris, concluindo que no grupo estudado houve efeitos benéficos.

Análises retrospectivas de cinco pacientes com SD, os quais apresentavam infecções recorrentes, revelaram que todos tinham níveis baixos de timulina. Três pacientes tinham baixos níveis de zinco, que normalizaram após reposição do mineral. Porém, os níveis de timulina foram persistentemente baixos em quatro dos cinco pacientes com SD, apesar de manterem níveis celulares normais de zinco ${ }^{48}$.

Disfunções imunes, níveis de zinco plasmático e presença de doença gastrointestinal foram investigados em 43 crianças com SD. Linfócitos T periféricos com fenótipos de células helper ou cluster de diferenciação 4 (CD4) estavam diminuídos. Células T ativas circulantes (CD3/HLA-DR-células positivas) e linfócitos granulares (CD16/CD56 células positivas) estavam aumentados. Níveis plasmáticos de interleucina-6 estavam mais altos em crianças com SD do que em controles $(n=18)$. Muitas dessas crianças mostraram níveis séricos aumentados de imunoglobulina-G (IgG) específica para antígeno de gliadina. O aumento sérico de interleucina- 6 estava relatado por idade e correlacionado com os níveis anti-gliadina IgG em SD. Os níveis de zinco no plasma estavam mais baixos em crianças com SD e doença celíaca e naqueles com anti-gliadina IgG, do que nas crianças com SD sem anti-gliadina lg $\mathrm{G}$ detectáve ${ }^{37}$.

No estudo já citado anteriormente, realizado por Romano et al.7, não foi encontrada nenhuma diferença significativa com relação aos anticorpos antigliadina, $\lg A$ e $\lg G$, presença de doença celíaca, relação CD4/CD8, imunoglobulinas $\mathrm{G}$ totais e subclasses, em comparação aos dois grupos com SD $(n=120)$, um com níveis normais de zinco e o segundo com níveis reduzidos do mineral.

\section{CONSIDERAÇÕ ES FINAIS}

Existem evidências experimentais que demonstram alterações na distribuição do zinco em organismos de indivíduos portadores da Síndrome de Down, bem como distúrbios bioquímicos, metabólicos e/ou hormonais, manifestados pela deficiência desse mineral. Várias pesquisas mostram os resultados promissores da suplementação com zinco na melhora de quadros clínicos, como o hipotireoidismo subclínico e alterações do sistema imune. Novos estudos sobre os mecanismos de interação do zinco diretamente com as enzimas que participam da conversão dos hormônios tireoidianos, ou influenciando a produção de citoquinas que participam do sistema imune, poderão fornecer bases para o entendimento bioquímico da interação desse mineral com as alterações hormonais e imunológicas na Síndrome de Down. O desdobramento desse conhecimento poderá nortear outros ensaios clínicos para estabelecer o potencial terapêutico do zinco sobre o hipotireoidismo, o estresse oxidativo e a deficiência do sistema imune. 


\section{REFERÊNCIAS}

1. Groner Y, Elroy-Stein O, Avaraham KB. Cell damage by excess Cu/Zn SOD and Down's sydrome. Biomed Pharmacother. 1994; 48(5-6):231-40.

2. Moreira LMA, El-Hani CN, Gusmão F. A síndrome de Down e sua patogênese: considerações sobre o determinismo genético. Rev Bras Psiquiatr. 2000; 22(2):96-9.

3. Kanavin OJ, Aaseth J, Birketvedt GS. Thyroid hypofunction in Down's syndrome: is it related to oxidative stress? Biol Trace Elem Res. 2000; 78 (1-3):35-42.

4. Bucci I, Napolitano G, Giuliani C, Lio S, Minnurucci A, Di Giacomo F, et al. Zinc sulfate supplementation improves thyroid function in hypozincemic Down children. Biol Trace Elem Res. 1999; 67(3):257-68.

5. Sandström B. Bioavailability of zinc. Eur J Clin Nutr. 1997; 1(Suppl):S17-S9.

6. Marreiro DN, Fisberg M, Cozzolino SMF. Zinc nutritional status and its relationships with hyperinsulinemia in obese children and adolescents. Biol Trace Elem Res. 2004; 100(2): 137-50.

7. Romano C, Pettinato R, Ragusa L, Barone C, Alberti $A$, Failla P. Is there a relationship between zinc and the peculiar comorbidities of Down syndrome? Down Syndr Res Pract. 2002; 8(1):25-8.

8. Nishiyama S, Futagoishi-Suginohara $Y$, Matsukura T, Higashi A, Shinohara M, Matsuda I, et al. Zinc supplementation alters thyroid hormone metabolism in disabled patients with zinc deficiency. J Am Coll Nutr. 1994; 13(1):62-7.

9. Cousins RJ, McMahon RJ. Integrative aspects of zinc transporters. J Nutr. 2000; 130(Suppl 5): 1384-7.

10. Hempe JM, Cousins RJ. Cysteine-rich intestinal protein and intestinal metallothionein: an inverse relationship as a conceptual model for zinc absorption in rats. J Nutr. 1992; 122(1):89-95.

11. Zhou JR, Erdman JW. Phytic acid in health and disease. Crit Rev Food Sci Nutr. 1995; 35(6): 495-508.

12. Lee HH, Prasad AS, Brewer GJ, Owyang C. Zinc absorption in human small intestine. Am J Physiol. 1989; 256(1 Pt 1):G87-91

13. Aggett PJ, Comerford JG. Zinc in human health. Nutr Rev. 1995; 53(9):S11-22.

14. Palmiter RD, Findley SD. Cloning and functional characterization of a mammalian zinc transporter that confers resistance to zinc. Embo J. 1995; 14(4):639-49.

15. McMahon RJ, Cousins RJ. Mammalian zinc transporters. J Nutr. 1998; 128(4):667-70.
16. Cousins RJ. Absorption, transport and hepatic metabolism of copper and zinc: Special referece to metallothionein and ceruloplasmin. Physiol Rev. 1985; 65(2):238-309.

17. Cousins RJ. A role of zinc in the regulation of gene expression. Proc Nutr Soc. 1998; 57(2):307-11.

18. Peretz A, Neve J, Jeghers O, Leclercq N, Praet JP, Vertongen $\mathrm{F}$, et al. Interest of zinc determination in leucocyte fractions for the assessement of marginal zinc status. Clin Chim Acta. 1991; 203(1):35-46.

19. Hinks LJ, Clayton BE. Zinc and copper concentratins in leucocytes and eritrocytes in healthy adults and the effect of oral contraceptives. J Clin Pathol. 1983; 36(9):1016-21.

20. Prasad AS. Clinical, biochemical and nutritional spectrum of zinc deficiency in human subjects: an update. Nutr Res. 1983; 41(7):197-211.

21. Cozzolino SMF. Biodisponibilidade de minerais. Rev Nutr. 1997; 2(10):87-98.

22. Maret W. Zinc biochemistry, physiology and homeostasis: recent insights and current trends. Bio Metal. 2001; 14:187-90.

23. Todd WR, Elvehjem CA, Hart EB. Zinc in the nutrition of the rat. Am J of Physiology. 1934; 107:146-56.

24. Sandstead HH. Understanding zinc: recent observations and interpretations. J Lab Clin Med. 1994; 124(3):322-7.

25. Vallee $\mathrm{BL}$, Falchuk $\mathrm{KH}$. The biochemical basis of zinc physiology. Physiol Rev. 1993; 73(1):79-118.

26. Szczurek El, Bjornsson CS, Taylor CG. Dietary zinc deficiency and repletion modulate metallothionein immunolocalization and concentration in small intestine and liver of rats. J Nutr. 2001; 131(8): 2132-8.

27. Prasad AS. Essential and toxic trace elements in human health and disease. New York: Alan R Liss; 1988. p.3-53.

28. Bray TM, Bettger WJ. The physiological role of zinc as an antioxidant. Free Radical Biol Med.1990; 8(3): 281-91.

29. Rascon MVT, Toledano FL, A-Villalobos VS. Evaluation of plasma zinc levels in patients with Down syndrome. An Esp Pediatr. 1992; 37:391-3.

30. Lima AS. Estado nutricional relativo ao zinco em pacientes com Síndrome de Down [dissertação]. São Paulo: Faculdade de Ciências Farmacêuticas; 2002.

31. Purice M, Maximilian C, Duritriu I, Ioan D. Zinc and copper in plasma and erythrocytes of Down's children. Endocrinologie. 1988; 26(2):113-7.

32. Napolitano G, Palka G, Lio S, Bucci I, De Remigis P, Stuppia L, Monaco F, et al. Is zinc deficiency a cause 
of hypotireoidism in Down syndrome? Ann Genet. 1990; 33(1):9-15.

33. Yenigun A, Ozkinay F, Cogulu O, Coker C, Cetiner $\mathrm{N}$, Ozzlen $\mathrm{G}$, et al. Hair zinc level in Down syndrome. Downs Syndr Res Pract. 2004; 9(2):53-7.

34. Soto-Quintana M, Nava A, Atencio F, Granadillo A, Fernádez $\mathrm{V}$, Ocando D, et al. Diminished zinc plasma concentrations and alterations in the number of lymphocyte subpopulations in Down's syndrome patients. Invest Clin. 2003; 44(1):51-60.

35. Siqueira WL, Oliveira E, Mustacchi Z, Nicolau J. Electrolyte concentrations in saliva of children aged 6-10 years with Down syndrome. Oral Surg. 2004; 98(1):76-9.

36. Licastro F, Mocchegiani E, Masi M, Fabris N. Modulation of the neuroendocrine system and immune functions by zinc supplementation in children with Down's syndrome. J Trace Elem Electrolytes Health Dis. 1993; 7(4):237-9.

37. Licastro F. Immune-endocrine status and celiac disease in children with Down's syndrome: relationships with zinc and cognitive efficiency. Brains Res Bull. 2001; 55(2):313-7.

38. De la Torre R, Casado A, Lopez-Fernandez E, Carrasosa D, Ramírez V, Saez J. Overexpression of copper-zinc superoxide dismutase in trisomy 21. Experientia. 1996; 52(9):871-3.

39. Neve J, Sinet PM, Molle L, Nicole A. Selenium, zinc and copper in Down's syndrome (trisomy 21): blood levels and relations with glutatione peroxidase and superoxide dismutase. Clin Clim Acta. 1983; 133(2):209-14.

40. Teksen F, Sayli BS, Aydin A, Sayal A, Isimer A. Antioxidative metabolism in Down syndrome. Biol Trace Elem Res. 1998; 63(2):123-7.

41. Lee M, Hyun D, Jenner $P$, Halliwell B. Effect of overexpression of wild-type and mutant $\mathrm{Cu} / \mathrm{Zn}$ -superoxide dismutases on oxidative damage and antioxidant defenses: relevance to Down's syndrome and familial amyotrophic lateral sclerosis. J Neurochem. 2001; 76(4):957-65.

42. Salnikow K, Gao M, Voiltkun V, Huang X, Costa M. Altered oxidative stress responses in nickel-resistant mammalian cells. Cancer Res. 1994: 54(24): 6407-12.

43. Antonucci A, Di Baldassarre A, Di Giacomo F, Stuppia L, Palka G. Detection of apoptosis in peripheral blood cells of 31 subjects affected by down syndrome before and after zinc therapy. Ultrastruct Patho. 1997; 21(5):449-52.

44. Lockitch G, Puterman M, Godolphin W, Sheps S, Tingle AJ, Quigley G. Infection and immunity in Down's syndrome: a trial of long-term oral doses of zinc. J Pediatr. 1989; 114(5):781-7.

45. Bjorksten B, Back O, Gustavson KH, Hallmans G, Hagglof B, Tarnvik A. Zinc and immune function in Down's syndrome. Acta Paediatr Scand. 1980; 69(2):183-7.

46. Sustrova M, Strbak V. Thyroid function and plasma immunoglobulins in subjects with Down's syndrome (DS) during ontogenesis and zinc therapy. J Endocrinol Invest. 1994; 17(6):385-90.

47. Licastro F, Chiricolo M, Mocchegiani E, Fabris N, Zannoti M, Beltrandi $E$, et al. Oral zinc supplementation in Down's Syndrome subjects decreased infections and normalized some humoral and cellular immune parameters. J Intellect Disabil Res. 1994; 38(Pt 2):149-62.

48. Brigino EN, Good RA, Koutsonikolis A, Day NK, Kornfeld SJ. Normalization of cellular zinc levels in patients with Down's syndrome does not always correct low thymulin levels. Acta Pediatr. 1996; 85(11):1370-2

Recebido em: 17/6/2005 Versão final reapresentado em: 7/2/2006 Aprovado em: 28/3/2006 